\title{
UTS CONFERENCE ON COSMOPOLITAN CIVIL SOCIETIES
}

\section{4-5 October 2007, University of Technology, Sydney, Australia}

\section{Call for Papers}

What does cosmopolitanism mean in an age where globalisation is accompanied by the War on Terror, and where unprecedented levels of international migration are accompanied by attacks on multiculturalism and heightened 'border security' politics?

What futures can we imagine for cosmopolitan civil societies as community advocates and organisations struggle against defunding and the silencing of independent voices?

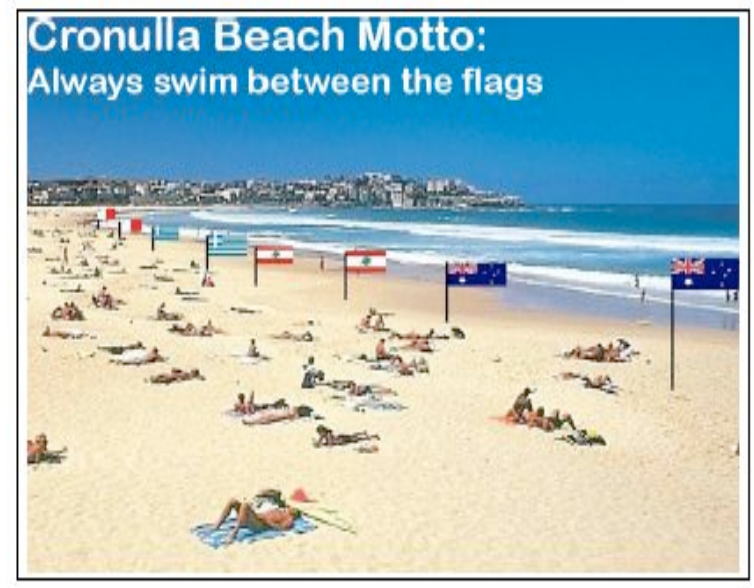

The UTS Centre for Cosmopolitan Civil Societies invites papers addressing these themes, which may include:

- Migration and civil societies

- Cosmopolitan cities and communities

- Cross cultural dialogues

- Civil societies and the third sector

- Community activism and social movements

- Cosmopolitan diversity and civil societies in developing nations

- Challenges and opportunities facing contemporary cosmopolitan societies

- Cultural differences and creative practices

- Popular education and cosmopolitan societies

International and Comparative Perspectives are invited, as are submissions for workshop proposals (11/2 hours). Submissions should be forwarded to ccs@uts.edu.au by 31 August 2007. Please include the Title of the Paper; an Abstract (200 words), a short biography (100 words) and the institutional details of presenter(s).

Peer Review: Full papers may be submitted for double blind peer review. To have your paper peerreviewed, please ensure that it is submitted by 13 August 2007. Alternatively, you may submit your abstract for refereeing, or submit an abstract to our unrefereed stream.

\section{Invited speakers include}

- Jan Rath, Professor of Urban Sociology, Director, Institute of Migration and Ethnic Studies, University of Amsterdam, The Netherlands

- Dan Hiebert, Professor of Geography, Director RIIM Centre, Canadian Metropolis, UBC, Canada

- Paul Spoonley, Professor of Sociology, Massey University, NZ

- David McEvoy, Emeritus Professor of Geography, Liverpool John Moores University, UK

- Stephen Castles, Professor of Migration \& Refugee Studies, Principal Research Officer for COMPAS \& a fellow at Green College, University of Oxford, UK

- Pieter Bevelander, Assoc. Professor, MIM, The Institute of Migration, Diversity \& Welfare and the IMER Department, Malmo University, Sweden

- David Ley, Professor of Urban \& Social Geography, University of British Columbia, Canada
Post-graduate research workshop: On Wednesday, 3 October, there will be a special full-day workshop on postgraduate research practices. Topics to be discussed will include methodology, research design and publication strategies.

There is no charge for this event. Please direct enquiries \& registrations to kirrily.jordan@student.uts.edu.au.

In addition, we encourage post-graduate students to submit abstracts for the main conference. We aim to publish refereed post-graduate student papers following the conference. 


\section{Publication:}

We are currently negotiating with the following journals (Portal Journal of Multidisciplinary International Studies, Gateways, Transforming Cultures and UTS epress) for special issues on themes emerging from the conference. Negotiations are also underway for the publication of a book of an edited collection of conference papers.

\section{Conference Rates:}

Early Bird Rates (payment by 31 August) Corporate/Government Academic

Full Rates

Corporate/Government

$\$ 400$ or $\$ 200$ per day Academic $\$ 200$ or $\$ 100$ per day

Special Rates:

UTS staff

$\$ 150$ or $\$ 75$ per day

Student

Community

NGOs

Low-income

$20 \%$ discount for Metropolis Conference attendees.

\section{Conference Registrations:}

Registration will only be available online. For details, please go to http://www. shopfront.uts.edu.au/news/ccs.html or contact ccs@uts.edu.au.
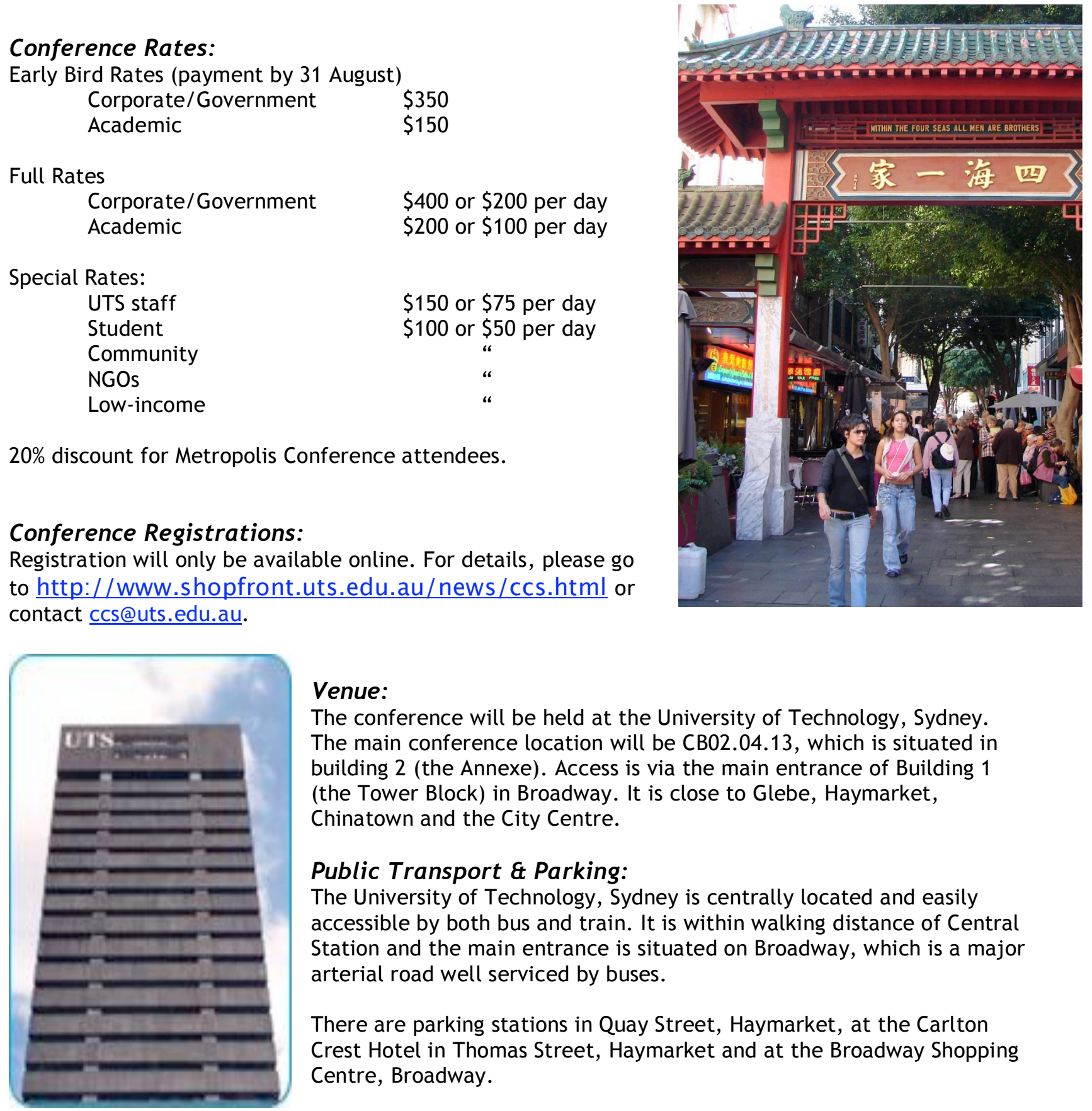

\section{Venue:}

The conference will be held at the University of Technology, Sydney. The main conference location will be CB02.04.13, which is situated in building 2 (the Annexe). Access is via the main entrance of Building 1 (the Tower Block) in Broadway. It is close to Glebe, Haymarket, Chinatown and the City Centre.

\section{Public Transport \& Parking:}

The University of Technology, Sydney is centrally located and easily accessible by both bus and train. It is within walking distance of Central Station and the main entrance is situated on Broadway, which is a major arterial road well serviced by buses.

There are parking stations in Quay Street, Haymarket, at the Carlton Crest Hotel in Thomas Street, Haymarket and at the Broadway Shopping Centre, Broadway.

\section{Accommodation:}

There are many well-priced hotels in the vicinity of UTS, for example, the Oaks Harmony at Haymarket ( $4 \frac{1}{2}$ stars), the Mercure (4 1/2 stars) and the Medina (4 stars) at Railway Square, the Carlton Crest at Haymarket ( 4 stars) and the Marque on the corner of Broadway and Quay Street (3 stars).

\section{Entertainment:}

Just a short stroll from the UTS campus is Chinatown with its huge variety of Chinese and other Asian restaurants. The surrounding area also has many other restaurants, pubs and cafes where conference attendees can relax together. To explore the local area online, visit 